\title{
La Comintern y el Partido Comunista del Paraguay, una historia de desencuentros
}

\author{
The Comintern and the Communist Party of Paraguay, \\ a permanent disagreement
}

\author{
Víctor Jeifets, Lazar Jeifets ${ }^{*}$
}

Resumen: El artículo analiza la primera etapa de las relaciones entre el Partido Comunista de Paraguay (PCP) y la Internacional Comunista (Comintern), cuando el PCP sufre la crisis interna y cambio de dirigencia como consecuencia de la ingerencia directa del Secretariado Sudamericano de la Comintern. El texto contiene también un esbozo de contactos mantenidos por Moscú y el PCP a lo largo de la década de 1930. Sobre la base de los documentos de la Comintern resguardados en Moscú, y algunos otros archivos, los autores recuperan una historia poco conocida en la historiografía de la izquierda paraguaya.

Palabras clave: Comintern; Partido Comunista de Paraguay; Secretariado Sudamericano; CEIC; Lucas Ibarrola; Victorio Codovilla

Abstract: The article analyzes, above all, the first stage of relations between the PC of Paraguay and the Communist International (Comintern), when the PCP suffered the internal crisis and change of leader as a consequence of the direct interference of the South American Secretariat of the Comintern. The text also contains an outline of contacts maintained by Moscow and the PCP throughout the 1930s. On the basis of the documents of the Comintern kept in Moscow, and some other archives, the authors recover a little-known history in the historiography of the Paraguayan left.

Keywords: Comintern, the Communist Party of Paraguay; South American Secretariat; ECCI; Lucas Ibarrola; Victorio Codovilla

Recibido: 2 febrero 2018 Aceptado: 15 abril 2018

\footnotetext{
* Víctor Jeifets. Ruso. Doctor en Historia. Profesor de Saint-Petersburg State University; profesor de la Universidad Estatal de Instrumentación Aerospacial de San Petersburgo. Coautor. jeifets@gmail.com

Lazar Jeifets. Ruso. Doctor en Historia. Profesor de Saint-Petersburg State University. Coautor. ilaranspb@hotmail.com
} 


\section{Introducción}

El Partido Comunista de Paraguay que cumplió 80 años en 2018, fue varias veces el principal referente de la historia gloriosa de las luchas obreras en la década de 1940, aunque luego fue marginado de la vida política y gremial a causa de las persecuciones feroces de parte de varias dictaduras, sobre todo la de Alfredo Stroessner. Sin embargo, páginas no menos interesantes de la historia del PCP se abrieron antes, en la segunda parte de la década de 1920, cuando el pequeño país sudamericano se convirtió en un campo de batalla entre el dirigente del PCP Lucas Ibarrola y el Secretariado Sudamericano de la Comintern (SSAIC). Era un choque de dos modelos: el de existencia relativamente autónoma de una sección nacional latinoamericana de la III Internacional (con la supuesta obediencia a los órganos supremos de la 'Internacional de Moscú') y el de establecimiento de un control estricto sobre las palabras y acciones de tales secciones por Moscú (que actuaba, a la vez, por conducto de su Secretariado Sudamericano con sede en Buenos Aires y controlado fuertemente por los comunistas argentinos; por lo tanto, para algunos militantes sudamericanos, el SSAIC no tanto era la representación cominternista, sino una 'Internacional de Buenos Aires').

La crisis del PCP en la década de 1960, provocó una discusión sobre los detalles de su fundación, sobre todo, por quienes y cuando fue creado el Partido Comunista. La sección "marxista-leninista" de la dirección del PC acusó al secretario general del Comité Central (CC), Oscar Creydt Abelenda, de serias falsificaciones sobre la verdad histórica y de las intenciones de crear un culto de personalidad basándose en su papel de "fundador del partido". Para contrarrestar estas acusaciones, los adversarios de Creydt enviaron a su representante a Moscú para estudiar los documentos del PCP y de la Comintern acumulados en el Archivo Central del Partido Comunista de la Unión Soviética (hoy día el Archivo Estatal Ruso de Historia Social y Política (RGASPI, por sus siglas en ruso). La importancia del viaje era imprescindible dado falta de acceso de público general a sus acervos. Solo algunos historiadores autorizados por los Comités Centrales de sus respectivos países tenían chance revisar algunos documentos y tampoco se les prestaba todo el conjunto de materiales.

El viaje era necesario, por la falta de archivos propios en el PCP, que había sido un partido clandestino durante décadas, expuesto a enjuiciamientos severos por las autoridades. El Partido Comunista de Paraguay no tenía ni podía disponer de ningún documento que permitiera un análisis objetivo y serio de su pasado histórico. Era y es un problema común para varios partidos de izquierda en Latinoamérica. Sin embargo, Paraguay mostraba el ejemplo más claro de tal carencia de fuentes: si en México, Cuba, Argentina y Brasil lograron resguardar, por lo menos, algunos materiales fragmentados, los izquierdistas paraguayos no fueron capaces de lograr eso.

Más tarde, sobre la base de varios materiales recopilados en la URSS, el historiador del PCP, Hugo Campos, restauró algunos aspectos de la historia del partido. Su libro, junto con las investigaciones hechas por los historiadores soviéticos Alexandr Petrujin, Evgeni Churilov y Vitali Jaritonov, hasta el día de hoy representan las fuentes principales sobre los primeros años 
del PCP. ${ }^{1}$ Sin embargo, se trata de información incompleta y procesada de acuerdo con los esquemas dogmáticos del marxismo-leninismo soviético, y que no presenta la complejidad de las relaciones entre el PCP y la Comintern. La escasez de documentos accesibles era solo uno de los factores. El otro era el afán de evitar referirse a ciertos episodios que no coincidieran con el esquema marxista de la formación y desarrollo del PCP, supuestamente arraigado en el movimiento obrero de su país y capaz de desempeñar una línea autónoma de conducta. A los historiadores referidos les costaba trabajo y, efectivamente, era imposible admitir la posibilidad de una injerencia directa de la sede de la Comintern y de sus representantes en el continente en la vida partidaria del PCP.

Las otras dos obras sobre Partido Comunista de Paraguay (que aparecieron en 1991 y 2001, ${ }^{2}$ respectivamente), tampoco aportaron datos nuevos sobre los acontecimientos de 1928-1929, por carecer de fuentes documentales sobre el período. De hecho, fueron más bien repetición de conclusiones anteriores, con la adición de algunos materiales hemerográficos. En general, la historiografía sobre el desarrollo del comunismo paraguayo es escasa, a diferencia de los PP.CC. de otros países del subcontinente latinoamericano. Además, la literatura existente se centra en personajes como Obdulio Barthé y Oscar Creydt, dejando en un olvido histórico los episodios importantes de los primeros años de existencia del PCP. Algunos aspectos de relaciones entre el dirigente del PCP Lucas Ibarrola y el SSAIC fueron tratados por los autores rusos Lazar y Victor Kheifets ${ }^{3}$, sin embargo, en aquel momento no pudieron acceder a varios documentos importantes que arrojan más luz sobre el tema. Tampoco pudieron tratar el asunto de relaciones entre el PCP y la III Internacional en la década de los 1930s.

Las obras generales sobre la relación entre la Comintern y América Latina tampoco son de gran ayuda, pues prestan poca atención a Paraguay. ${ }^{4}$ Estos estudios no arrojan luz sobre el importantísimo tema de la influencia de la Comintern y su organismo regional, el SSAIC, en la formación del comunismo paraguayo. La vida interna del PCP y sus enlaces gremiales están en cierto grado analizados por Francisco Gaona (él mismo era uno de los personajes clave en la historia de la izquierda paraguaya y en el movimiento sindical de su patria), sin embargo, el autor casi no se refiere a la historia de relaciones entre el PCP y Moscú. ${ }^{5}$ El presente artículo tiene la intención de cubrir estos aspectos a base de documentos de archivo no utilizados anteriormente.

Comenzamos con la necesidad de prestar mayor atención al período inicial del PCP, partiendo del momento de su inserción en la órbita del comunismo internacional. Creemos

\footnotetext{
${ }^{1}$ Hugo Campos, Panorama del Paraguay, [Asunción], Editorial Alas, 1970, 205; Aleksandr A. Petrujin, Evgenii M. Churilov, Kebracho - znachit stoikii, Moscú, Politizdat, 1981; Vitalii A. Jaritonov, Paragvai. Voennopolitseiskaia diktatura i politicheskaia bor'ba, Moscú, Nauka, 1970.

2 Antonio Bonzi, Proceso histórico del Partido Comunista Paraguayo (Un itinerario de luces y sombras), Asunción, Arandura Editorial, 2001; Humberto Rosales, Historia del Partido Comunista Paraguayo, 1928-1990, Asunción, PCP Editor, 1991.

${ }^{3}$ Lazar Kheifets y Victor Kheifets, "The "International of Moscow" or the "International of Buenos Aires"?", The International Newsletter of Communist Studies, 2012, vol.18, N.25, PP. 123-136.

${ }^{4}$ Manuel Caballero, La Internacional Comunista y la revolución latinoamericana, Caracas, Editorial Nueva Sociedad, 1987; Boris Goldenberg, Kommunismus in Lateinamerika, Stuttgart, Berlin, Köln, Mainz, Kohlhammer, 1971; Robert J. Alexander, Communism in Latin America, New Brunswick, N. J., Rutgers University Press, 1957.

${ }^{5}$ Francisco Gaona, Introducción a la bistoria gremial y social del Paraguay, Tomo 1, Asunción - Buenos Aires, Editorial "Arandu", 1967, Tomo 2, Asunción, Editora Litocolor, 1987.
} 
necesario matizar y profundizar el estudio, llenando la laguna existente en la historiografía. Dentro de los marcos de presente artículo se pretenden recuperar los datos históricos sobre los primeros contactos establecidos entre el PCP, la sede de la Comintern y su representación regional bonaerense. Al respecto, sostendremos que estos primeros contactos dejaron en evidencia las contradicciones entre el modelo del 'comunismo nacional' planteado por su fundador, Lucas Ibarrola, y la imposición por parte del SSAIC, cuyo mayor protagonista en el momento era el argentino Victorio Codovilla. En su lucha "contra la Internacional de Buenos Aires” Ibarrola perdió rotundamente, dejando así el camino libre para la transformación del PCP y el seguimiento de la línea trazada por los representantes de la revolución proletaria victoriosa.

Para alcanzar nuestros objetivos, hemos elaborado un texto dividido en tres secciones. En la primera nos concentraremos en la historia de los primeros contactos establecidos entre el grupo comunista paraguayo y Moscú, destacando puntos de coincidencia y desencuentros con la Comintern. Luego, abordaremos el análisis de la esencia del conflicto entre los dirigentes del PCP y el Secretariado Sudamericano, considerando los detalles de las posturas tomadas por Ibarrola y por su adversario, Victorio Codovilla. En la tercera parte, nos dedicaremos al estudio del proceso de transformación del PCP en la fase final del conflicto con el SSAIC, tras la expulsión de Ibarrola. En esta misma sección nos concentraremos brevemente en la historia de relaciones entre el PCP y la Comintern en la década de 1930.

Utilizaremos algunas fuentes hemerográficas (aunque no son muchas en este caso), en especial los materiales de la revista del SSAIC, "La Correspondencia Sudamericana", para obtener información sobre varios aspectos de la historia del PCP. Sin embargo, la base principal del artículo son los documentos de archivos rusos, la correspondencia entre el PCP, el SSAIC y la Comintern, así como las actas de sesiones del CC del PCP resguardados en Moscú. Sobre todo, nos interesa el análisis de la correspondencia secreta, con el propósito de averiguar los pormenores de la izquierda comunista de Paraguay de aquel período. Hemos contrastado las fuentes de archivo con la poca bibliografía referente al tema, usando, enfoque que nos ayuda a recuperar paulatinamente la historia del establecimiento y desarrollo de relaciones entre el comunismo mundial y su sección nacional en Paraguay.

\section{Los inicios de las relaciones entre el PCP y la Comintern}

Tras su V Congreso, en 1924, la Comintern se interesó seriamente -por primera vez- en la formación de nuevas secciones nacionales en Sudamérica. Esta era una de las tareas encomendadas al Secretariado Sudamericano de la IC, creado en Buenos Aires en 1925, bajo el liderazgo de José F. Penelón, uno de los dirigentes históricos del PC de Argentina y el miembro del CEIC. Al SSAIC le tocaba coordinar el naciente movimiento comunista en la región ayudando, a la vez, al establecimiento de enlaces entre Moscú y los grupos y partidos comunistas locales. ${ }^{6}$ Estos trabajos -a excepción de Uruguay y, parcialmente, de Chile- nunca fueron tan exitosos como Penelón los solía pintar en sus informes. Paraguay fue uno de los

${ }^{6}$ Víctor Augusto Piemonte, "La Internacional Comunista y los comienzos del Secretariado Sudamericano a través de la sistematización regional del proceso de bolchevización”, Historia Crítica, 64, Bogotá, 2017, $108-112$. Desafortunadamente, el autor no se refiere al trabajo del SSAIC en relación a Paraguay. 
países donde el SSAIC no logró llegar durante años, y el movimiento obrero y comunista tampoco era muy fuerte.

A inicios del siglo XX Paraguay seguía siendo un país predominantemente agrario y no disponía de una clase obrera influyente. Incluso a finales de los años veinte y principios de los treinta, la base económica de la sociedad eran los campesinos, con algunas inserciones de obreros portuarios. ${ }^{7}$ Los grandes centros gremiales no existían. La Federación Obrera Regional del Paraguay, FORP, fundada por José Cerrano en 1906, dejó de funcionar en 1915. El anarcosindicalista Centro Obrero Regional del Paraguay -creado sobre su base- carecía de influencia. ${ }^{8}$ El nacimiento de la izquierda fue, como lo nota R. Medina, predominante un fenómeno urbano en un país casi completamente agrario, donde dominaba el discurso de los partidos tradicionales, especialmente del Partido Colorado. ${ }^{9}$ El Partido Comunista, de existencia virtual, no tenía una cantidad adecuada de adherentes, por la escasez del proletariado. El apoyo de los campesinos, a su vez, violaría los postulados básicos del marxismo y no permitiría formar un partido proletario.

No hay que sorprenderse de que los primeros grupos socialistas y comunistas en Paraguay fueron fundados por los intelectuales. En 1914, Rufino Recalde Milesi anunció la formación del Partido Socialista Revolucionario del Paraguay, sobre la base de varios grupos dispersos. El PSRP editaba la revista "Voz del Pueblo" e intentaba plantear reivindicaciones obreras. No tuvo muchos partidarios, sin embargo, estableció algunos contactos en el extranjero, sobre todo con los socialistas y sindicalistas de Uruguay y Argentina. En 1919 participó en una conferencia socialista y obrera en Buenos Aires. ${ }^{10}$ No obstante, nunca llegó a convertirse en un actor influyente en la vida política paraguaya ni en la vida sindical. Tampoco fue la base para formar un grupo comunista.

El PCP considera el 19 de febrero de 1928 como la fecha oficial de su fundación, ${ }^{11}$ aunque la actividad comunista había comenzado algunos años antes. ${ }^{12}$ Los materiales de la Conferencia Nacional Preparatoria para el III Congreso del PCP contienen varios datos sobre las actividades de un grupo marxista en Asunción en 1922-1923 y sus luchas contra el gobierno considerado por los izquierdistas- como "cómplice de los imperialismos americano e inglés". Este primer grupo comunista aparece formalmente en 1924, compuesto de estudiantes y unos pocos obreros bajo el nombre de Comité de Acción Social. El Comité no disponía de recursos financieros y no funcionaba de una manera activa por miedo a las persecuciones gubernamentales. Al mismo tiempo, a fines de 1924, envió su delegado a Buenos Aires para reunirse con los líderes del Partido Comunista de la Argentina (PCA) y discutir con ellos cuestiones de trabajo revolucionario y movimiento de clase en Paraguay.

El plan del grupo era lograr el viaje a Paraguay de algunos "camaradas" argentinos para que pudieran ayudarlos en la creación de un Partido Comunista. Sin embargo, tanto el PCA como

\footnotetext{
7 Robert J. Alexander, A History of Organized Labor in Uruguay and Paraguay, Greenwood Publishing Group, 2005, 88.

${ }^{8}$ Ibid., 92-94.

${ }_{9}$ Ricardo Medina, The Left, Peter Lambert\&Andrew Nickson, The Transition to the Democracy in Paraguay, London, Macmillan Press Ltd, 79-82.

10 J.Carriere, N.Haworth, J.Roddick, The State, Industrial Relations and the Labour Movement in Latin America, Volume 1, Springer, 1989, 70.

${ }^{11}$ K. I. Zarodov (ed.), Kommunisty mira - o svoikh partiiakh, Praga, Mir i sotsializm, 1976, 188.

${ }^{12}$ Campos, op. cit., 205; Relatorio sobre la actividad enemiga de Oscar Creydt, s.l., abril 1967, 16.
} 
el Secretariado Sudamericano de la Comintern no hicieron prácticamente nada para apoyar a los dispersos grupos comunistas del país vecino: Paraguay no fue considerado como una prioridad para el movimiento comunista sudamericano a diferencia de Argentina, Chile y Uruguay. Sólo durante los preparativos para el IV Congreso de la Internacional Sindical Roja (1928) (e indudablemente, esto tenía que ver con los llamados insistentes de Moscú de aumentar la presencia latinoamericana en los congresos de la Comintern y la ISR), el Secretario General del PCA, Pedro Romo, estableció contactos con Moisés Drelijman, uno de los líderes comunistas paraguayos, para conocer las perspectivas del movimiento obrero y, en consecuencia, la posibilidad de realizar actividad comunista.

Romo envió algunos materiales de propaganda e instrucciones para la reorganización del grupo comunista de Asunción, logrando hacer lo que no había podido realizar el SSAIC en la época de Penelón: el recién fundado PC de Paraguay declaró su afiliación a la Internacional Comunista el 19 de febrero de 1928. El Partido había anunciado la creación de un gobierno de trabajadores, campesinos y soldados después de la revolución social como su objetivo político; más tarde, los comunistas planearon construir "el socialismo completo [...] y su posterior transformación al comunismo". ${ }^{13}$ Aunque estas palabras no cambiaron la cotidiana práctica política de los pequeños grupos comunistas en Paraguay, políticamente fueron llevados, a partir de ese momento, a la órbita del comunismo mundial.

El líder del PCP, Lucas Ibarrola, informó al Comintern de tres mil adherentes en todo el país, lo que estaba lejos de ser verdad. El mismo dirigente comunista paraguayo reconoció que el programa del PCP no existía, admitió que el trabajo partidario solo se llevaba a cabo de manera esporádica y que el único intento por hacer el PCP atractivo para las masas, había sido lanzar la consigna "La tierra a sus antiguos propietarios, los indígenas, a quienes les echan fuera de las tierras periódicamente". Ibarrola tuvo que confesar: "El P.[artido], pues, como organización, no existe". ${ }^{14}$ Efectivamente, sólo había un grupo de 20 militantes en Asunción que había elegido un Comité Central; el PCP no disponía de militantes en el interior del país. Durante su sesión, este Comité Central se ocupó de la admisión de miembros individuales al PCP, otra indicación de la escasez numérica del Partido recién nacido. Casi todos los comunistas paraguayos se conocían personalmente. Tal situación no era algo raro para el comunismo latinoamericano tomando en cuenta el reducido contingente de la mayoría de los PP.CC., sin embargo, aun comparando con los demás partidos comunistas, la situación paraguaya era excepcional.

La cuestión paraguaya fue tema importante en la lucha faccional ocurrida en el PCA y que paralizó la actividad del SSAIC en 1927-1928. El PCP como tal interesaba muy poco a los dirigentes comunistas argentinos, sin embargo, podía convertirse en una herramienta más para dañar a sus adversarios dentro del PC de Argentina. Pedro Romo, que era uno de los líderes de la facción de la mayoría, logró demostrar a Moscú que las estructuras de la Comintern podían operar con éxito a escala continental. Al mismo tiempo, señaló que su adversario, Penelón, era un obstáculo para el trabajo organizativo del Secretariado Sudamericano. Romo destacó en su

13 “A los habitantes de la República. Partido Comunista. Sección paraguaya de la Internacional Comunista', Los Comuneros, Asunción, 19 de febrero de 1928; Petrujin y Churilov, op. cit., 9.

${ }^{14}$ Declaraciones e informaciones del Camarada Lucas Evangelista Ibarrola de Paraguay, 1928. RGASPI, Moscú. F. 495, inv. 117, exp. 5, f. 1; Acta №3 de la sesión del CC del PCP. Asunción, 27 de enero de 1929; Acta №4 de la sesión del CC del PCP. Asunción, 5 de Febrero de 1929. RGASPI, Moscú. F. 495, inv. 117, exp. 6, fs. 18 , 20. 
informe al Comité Ejecutivo de la Internacional Comunista (CEIC) que, "por inexistencia del Secretariado Sudamericano, reducido hoy a lo poco", este quehacer regional se reducía a lo que él "estaba haciendo personalmente". ${ }^{15} \mathrm{Al}$ mismo tiempo, afirmó que el Manifiesto emitido por los comunistas paraguayos era fruto exclusivo de su propio trabajo y fue preparado por iniciativa local; por eso, no asumiría la responsabilidad política por la actividad del PC del Paraguay: "Omito opinar sobre el mismo, dado que no tengo función alguna a este respecto". ${ }^{16}$ Esta fue una señal inequívoca para el CEIC de que estos poderes eran necesarios para dar un nuevo impulso a las actividades del Secretariado Sudamericano. Moscú percibió con gran entusiasmo la nota sobre la creación de una nueva sección de la III Internacional en América del Sur.

Se consideró bastante importante, ya que coincidió con los esfuerzos por ampliar la actividad propagandística de la Internacional Comunista antes del VI Congreso Mundial, cuando Moscú apostaba a establecer sus secciones en cada rincón del continente y a engrosar sus filas. Por lo tanto, el Secretariado del CEIC se apresuró en responder al Manifiesto del PCP, enviando una carta a su Ejecutivo y expresando la esperanza de un inicio exitoso de sus actividades revolucionarias entre las masas explotadas de trabajadores y campesinos de Paraguay. El CEIC solicitó establecer un estrecho contacto con Moscú mientras se mantenían las relaciones con el Secretariado Sudamericano. ${ }^{17} \mathrm{Al}$ mismo tiempo, el secretario del CEIC, el suizo Jules Humbert-Droz, aconsejó al SSAIC que estableciera contactos con el PCP y que lo ayudara dentro de sus posibilidades. ${ }^{18}$

Sin embargo, este mensaje apenas tuvo algún efecto pues Penelón había guardado casi todos los materiales del Secretariado durante la lucha interna del PCA, ausentándose por completo de las actividades exteriores del SSAIC. Los líderes de PCA y los miembros del SSAIC, Victorio Codovilla y Rodolfo Ghioldi, también se centraron en la lucha interna de su propio partido y no tuvieron mucho tiempo para dedicarlo a Paraguay. El único miembro activo del Secretariado Sudamericano en este momento era Pedro Romo, y fue él quien había organizado la carta de los paraguayos al Comintern.

El Partido Comunista Mundial no sabía casi nada sobre el nuevo candidato a miembro, una prueba más de la poca eficiencia de Penelón como jefe del SSAIC. Mientras la búsqueda de nuevos adherentes para la causa comunista fue una de las prioridades para el Secretariado Sudamericano, Penelón no hizo esfuerzos para expandir la influencia del centro regional de la Comintern durante los dos años de su permanencia en el cargo. ${ }^{19}$ El jefe del Secretariado Latino del CEIC tuvo que pedir al líder comunista paraguayo, Lucas Ibarrola, que enviara un informe sobre la situación económica y política del país, comunicar el número de militantes del Partido y describir su estructura organizativa, así como informar sobre publicaciones periódicas comunistas y las posibilidades de trabajo legal, sobre organizaciones sindicales y campesinas en

\footnotetext{
15 Informe de P.Romo al CEIC. 12 de marzo de 1928. RGASPI, Moscú. F. 495, inv. 117, exp.6, f. 2ob.

16 Idem.

${ }^{17}$ Manifesto del Secretariado del CEIC enviado al Comité Ejecutivo del Partido Comunista Paraguayo. Moscú, 19 de abril de 1928. RGASPI, Moscú. F. 495, inv. 117, exp. 1, f. 2.

${ }^{18}$ J. Humbert-Droz al Secretariado Sudamericano de la Comintern. 19 de abril de 1928. RGASPI, Moscú. F. 495, inv. 117, exp. 19, f. 1.

${ }^{19}$ Más detalle véase en: Lazar Jeifets, Víctor Jeifets, El Partido Comunista de Argentina y la III Internacional. La misión de Williams y los origenes del penelonismo, México, D.F., Nostromo Ediciones-Universidad Estatal de San Petersburgo, Instituto de América Latina de ACR, 2013, 101-135.
} 
Paraguay y la influencia del partido dentro de estas organizaciones. Moscú también estaba interesado en el tema de la penetración imperialista y en la existencia de un movimiento antiimperialista. ${ }^{20}$ Notemos que la actitud del CEIC hacia la nueva sección paraguaya careció de un enfoque especial para tomar en cuenta las realidades del país; precisamente el mismo cuestionario fue enviado al Partido Socialista Revolucionario de Colombia y al Partido Socialista Ecuatoriano y, al igual, que el PCP, pronto ambos pasarían por el doloroso episodio de la 'bolchevización' y 'proletarización'.

En su correspondencia con Moscú, Ibarrola adoptó una actitud bastante realista para estimar la situación del movimiento obrero paraguayo, señalando que estaba mal organizado y carecía un programa definido de acción. Confirmó que no había relaciones entre los comunistas paraguayos y el movimiento comunista mundial debido a los temores de ser incluidos en la esfera de "influencia de la Internacional Comunista", lo que causaría un sombreado permanente de la actividad comunista por parte del gobierno. ${ }^{21}$ El líder del PCP aseguró que sería realmente peligroso provocar al gobierno que tenía "miedo a la influencia argentina y rusa" y, por lo tanto, no dudaría en lanzar persecuciones anticomunistas. Así, los comunistas tratarían de llevar a cabo su trabajo de propaganda en una forma 'prudente', sin una declaración abierta de sus puntos de vista y sin establecer vínculos internacionales irritantes para las elites políticas locales. ${ }^{22}$

Esta falta de voluntad para mantener contactos con el PCA, fue la lógica consecuencia de la actitud personal de Ibarrola, que consideraba al PCA como un "Partido de sordomudos" y que limitaba los enlaces internacionales a la correspondencia con Penelón. ${ }^{23}$ Los "tutores" de Buenos Aires habían advertido al PCP que era imposible limitarse a las conversaciones sobre la revolución social mientras que los trabajadores no entendieran de qué se trataba.

Los líderes del PCA querían que sus adherentes en Paraguay expresaran las demandas inmediatas de la clase trabajadora, y les enseñaban los conceptos básicos de propaganda y organización. Los comunistas paraguayos, a su vez, intentaron explicar el comunismo a los campesinos indígenas como "una simple expresión de ideas comunales campesinas" (la tierra y los medios de producción deberían pertenecer a todas las personas, y los explotadores deben desaparecer), mientras que su línea de propaganda entre los trabajadores de la ciudad fue ligeramente diferente: el PCP hablaba sobre la jornada laboral de ocho horas, la socialización y el aumento de los salarios, tratando de dejar claro que los socialistas sólo querían obtener algunas posiciones parlamentarias al igual que todos los demás partidos, mientras que los comunistas habían comenzado una lucha abierta con el propósito de liberar a los trabajadores. ${ }^{24}$ Los comunistas paraguayos consideraron que el proletariado, "que estaba percibiendo las ideas comunistas con interés", era, desde su punto de vista, "mal adaptado para la lucha y reacio a seguir el camino de los sacrificios por nuestra causa". ${ }^{25}$

Ibarrola expuso, sin falsa modestia, que los éxitos logrados eran "fruto de los esfuerzos de las pocas personas que encabezaban el Comité” (del PCP), y propuso, en evidente

\footnotetext{
${ }^{20}$ Manifesto del Secretariado del CEIC enviado al Comité Ejecutivo del Partido Comunista Paraguayo, f. 2.

${ }^{21}$ L. Ibarrola a J. Humbert-Droz. 5 de Junio de 1928. RGASPI, Moscú. F. 495, inv. 117, exp. 6, fs. 4-5.

22 [L. Ibarrola]. Memorandum. 1928. RGASPI, Moscú. F. 495 ,exp. 117, exp. 5, f. 3.

${ }^{23}$ CC del PCP al Secretariado Latino del CEIC. 5 de julio de 1929. RGASPI, Moscú. F. 495, inv. 117, exp. 6, f. 39

${ }^{24}$ Declaraciones e informaciones del Camarada Lucas Evangelista Ibarrola de Paraguay, 1-2.

${ }^{25}$ L. Ibarrola a J. Humbert-Droz. 5 de junio 1928, 4.
} 
contradicción con las tesis de la Comintern, que los intelectuales deberían liderar al partido, ya que los “[o]breros aún no están preparados”. La dirección del PC de Paraguay consistía, de hecho, en un inspector de impuestos, dos joyeros, un pequeño comerciante y un zapatero. El grupo comunista de Asunción, además, incluyó a dos estudiantes y un empleado. Según la estimación de Ibarrola, la composición social del Ejecutivo no difería de la del partido. ${ }^{26}$ Tarde o temprano, esto debería convertirse en un nudo de contradicción con la Comintern que estaba a punto de entrar a la fase de lucha del 'obrerismo' en contra de los 'intelectuales' dentro de sus secciones nacionales.

\section{Victorio Codovilla vs. Lucas Ibarrola}

La actitud ideológica y las actividades prácticas del PCP no causaron mucho entusiasmo entre los nuevos líderes del SSAIC que ocuparon sus puestos tras la expulsión de Penelón del PCA, en 1928. Hubo, al menos, tres razones para su disgusto con el PCP: en primer lugar, el joven Partido Comunista no se adecuaba a las "21 condiciones" de la Comintern; en segundo lugar, el nuevo dirigente del Secretariado, Victorio Codovilla, no estaba satisfecho con el papel de Pedro Romo como fundador de nuevas secciones de la III Internacional. Y, por último, pero no menos importante, a Codovilla no le gustó Lucas Ibarrola, y le había declarado la guerra de inmediato. Tuvo que aceptar el hecho de que Ibarrola viajara a Moscú como delegado al VI Congreso Mundial (1928), aunque estaba seguro de que el Secretario General del PCP carecía de una mentalidad comunista. Los motivos de la decisión de Codovilla eran obvios y simples: "los camaradas-trabajadores con mayor nivel político" (jlos orígenes proletarios eran uno de los pre-requisitos exigidos por la Comintern!) no tenían posibilidades de salir de Paraguay. El SSAIC todavía intentó hacer que Ibarrola regresara de Argentina a su país y encontrar un sustituto para él, pero no había dinero ni tiempo para tal operación. ${ }^{27}$

Por ende, el proceso de la estalinización creciente de la Comintern -una etapa lógica de la ‘bolchevización' iniciada en 1924-1925-, exigía establecer el control más estricto sobre los PP.CC., lograr su proletarización (incluyendo a nivel de los dirigentes) y que obedecieran sin resistencias las decisiones tomadas por el CEIC o por sus estructuras regionales. La nueva táctica de "clase contra clase" que ya estaba fraguándose dentro del Estado Mayor de la Comintern, no admitiría el tipo de relaciones que habían sido establecido el PCP y el gobierno del país.

El Secretariado Sudamericano sostuvo que la situación en el PCP era bastante característica de los países coloniales donde el movimiento comunista y de los trabajadores a menudo estaba encabezado por intelectuales y, en consecuencia, este secretariado regional generó su propia agenda para proporcionar a los izquierdistas paraguayos "una ayuda personal", para formar y capacitar para el liderazgo futuro de un "movimiento comunista de masas". Cabe notar que, al mismo tiempo, la Comintern demandó a otros partidos sudamericanos, como el Partido

\footnotetext{
${ }^{26}$ Declaraciones e informaciones del Camarada Lucas Evangelista Ibarrola de Paraguay, 1-2.

27 Informe №4 del Secretariado Sudamericano de la Comintern al Secretariado Latino de la Comintern. Buenos Aires, 5 de julio de 1928. RGASPI, Moscú. F. 503, inv. 1, exp. 19, f. 21.
} 
Socialista Revolucionario de Colombia y el Partido Socialista de Ecuador, cumplir con más requisitos para ser admitidos finalmente en el seno de la III Internacional. ${ }^{28}$

La situación parecía paradójica. Mientras Ibarrola se dirigía a Europa junto con la delegación del PCA y planeaba participar en el Congreso Mundial de la III Internacional, demostrando con su presencia que la Comintern estaba ganando más influencia en Sudamérica, los representantes regionales de la Internacional estaban haciendo planes para sacarlo del liderazgo del PCP. El 1 de septiembre de 1928, el $6^{\circ}$ Congreso Mundial aprobó una resolución confirmando que el PCP era una sección de la Comintern sin ninguna reserva, pero ya el 5 de julio el SSAIC había organizado el viaje de un miembro de su Secretariado, Astrogildo Pereira (Secretario General del PC de Brasil) a Asunción con el propósito de "reorganizar el Partido y elevar su nivel político". ${ }^{29}$

El "caso Ibarrola", efectivamente, fue organizado por el mismo Codovilla para demostrar su autoridad como nuevo dirigente del SSAIC. A diferencia del "caso Celestino Mibelli" (quien antes había sido expulsado del PC del Uruguay bajo acusación de desviación parlamentarista) donde el emisario de la Comintern "Williams" (Boris Mijailov) sólo tuvo que lograr solución de un conflicto real, la situación en Asunción fue muy diferente. Este último 'conflicto' fue mero invento de Codovilla. El "caso Ibarrola" fue una oportunidad perfecta para que el Secretariado Sudamericano demostrara el nuevo carácter de las relaciones entre los órganos supremos de la Comintern en el continente y las secciones nacionales de la Internacional, la hegemonía del SSAIC dentro del comunismo latinoamericano, así como para mostrar el funcionamiento de la disciplina del partido internacional.

Codovilla, como experimentado burócrata partidario, entendió perfectamente que se requerían algunos argumentos fuertes para realizar cambios personales en el PCP. Es por eso que los comunistas argentinos organizaron el lanzamiento de un manifiesto -emitido por algunos comunistas paraguayos- dirigido al PC de Uruguay, el que, a su vez, notificó al SSAIC sobre un supuesto y grave descontento dentro del PCP con el viaje de Ibarrola a la URSS. ${ }^{30}$ Estas actividades dieron al SSAIC razones oficiales para enviar un delegado con el propósito de analizar las condiciones locales y "orientar a los camaradas".

Sólo después del regreso de Ibarrola de Moscú estalló la crisis interna del partido, provocando la reacción inmediata de la Comintern y de su Secretariado bonaerense. No hubo más tiempo que esperar, ya que la situación dentro del movimiento de los trabajadores cambió drásticamente debido a las circunstancias externas. Después de que el ejército paraguayo atacara el fortín boliviano Vanguardia, en diciembre de 1928, las relaciones entre ambas naciones se deterioraron seriamente y la guerra se hizo inminente. ${ }^{31}$ Las nuevas condiciones llevaron al PCP a estar entre los puntos prioritarios en la agenda de la Comintern.

28 VI kongress Kominterna. Stenograficheskii otchet. Tezisy, resoliutsii, postanovlenïa, vozzvanïa, Moscú-Leningrado, Gosizdat, 1929, 174.

${ }^{29}$ Informe №4 del Secretariado Sudamericano, 21.

30 Acta de la sesión del Secretariado Sudamericano de la Internacional Comunista. Buenos Aires, 14 de julio de 1928. RGASPI, Moscú. F. 503, inv. 1, exp. 21, f. 53.

31 Nikolai P. Kalmykov (ed.), Istoriia Latinskoi Ameriki. 1918-1945, Moscú, Nauka, 1999, 239-240. 
Este joven partido, según Humbert-Droz, "debe ser la primera de nuestras secciones que tiene que llevar a cabo la tarea histórica de aplicar las tácticas comunistas contra la guerra". ${ }^{32}$ Ibarrola destacó su comprensión en la influencia del conflicto paraguayo-boliviano para la lucha de clases en el país, asunto que se hacía notar en el primer informe a la Comintern: la captura de tierras pertenecientes a las empresas estadounidenses y británicas en una zona disputada generó un sentimiento de patriotismo entre los paraguayos que protestaban contra la presión extranjera. Según la Comintern, el suelo era "fructífero" para las actividades comunistas. ${ }^{33} \mathrm{Al}$ mismo tiempo, Humbert-Droz señaló que el "anti-yanquismo se había convertido casi en un culto religioso patriótico de la población a causa de los problemas internacionales y el importante papel desempeñado por los estadounidenses en estos temas"34 (se refirió al apoyo moral a Bolivia por parte de los Estados Unidos). Esto complicaba la tarea encomendada por la Comintern a su sección paraguaya: intentar convertir la guerra en una guerra civil logrando unidad de obreros bolivianos y paraguayos. El gobierno de Paraguay demostró capacidad para reunir a todos los sectores de la sociedad alrededor de la agenda patriótica, de modo que el PCP se encontró ante el dilema: o solidarizarse con los partidos burgueses o convertirse a la minoría absoluta y 'traidora' perdiendo la poca influencia que tenía.

Ibarrola prefirió hablar sobre la importancia del conflicto bélico para el aumento del patriotismo en vez de estimar las perspectivas del movimiento obrero y la posibilidad de cambiar el carácter de la guerra. En ese momento, la Comintern no se dio cuenta (o no quiso darse cuenta) del enfoque "no marxista" del secretario general del PCP respecto a este asunto extraordinariamente importante. Sólo en las condiciones de creciente oposición, cuando los sentimientos chauvinistas fueron calentados por los gobiernos de ambos países -así como por monopolios británicos y estadounidenses que competían por influencia en las áreas de conflicto--, ${ }^{35}$ el Secretariado Sudamericano condenó tajantemente la actitud de Ibarrola. El punto de vista del Secretario General del PCP fue también criticado duramente por la Primera Conferencia Comunista Latinoamericana, en Buenos Aires, en 1929.

Ibarrola vio en el conflicto boliviano-paraguayo una posibilidad para sacar a las masas de la influencia del chauvinismo gubernamental y explicarles las contradicciones antiimperialistas como la verdadera esencia del conflicto. El Secretariado Sudamericano, a su vez, estaba reduciendo la interpretación del conflicto boliviano-paraguayo, centrándose en las contradicciones antiimperialistas como la única causa de tensión. Victorio Codovilla atacó con furia al editor del periódico Justicia, del PC de Uruguay, Juan Greco, quien no quiso tomar una postura beligerante en este asunto. El representante de la Internacional de las Juventudes Comunistas en el SSAIC, Zacharii Rabinovich ("Pierre"), también insistía en que era necesario

\footnotetext{
32 Secretario del Secretariado Latinoamericano de la Comintern al Secretariado del Partido Comunista de Paraguay. Moscú, 18 de febrero de 1929. RGASPI, Moscú. F. 495, inv. 117, exp. 1, f. 5.

${ }^{33}$ L. Ibarrola a J. Humbert-Droz. 5 de junio de 1928, 7.

34 [L. Ibarrola]. Memorandum, 3.

35 L. Iu. Korableva, "Vmeshatel'stvo Ligi Natsii v uregulirovaniie boliviisko-paragvaiskogo konflikta 1928-1938 gg.", Latinoamerikanskii istoricheskii almanakh, 1, Moscú, 2000, 133.
} 
evitar la visión del conflicto como "una guerra entre un país antiimperialista y un país que se convirtió en un agente de imperialismo". 36

Mientras tanto, el PCP (o más bien Ibarrola) abogó por dar pasos cautelosos, lo que fue considerado como pasividad por el SSAIC. Codovilla exigió lanzar consignas de lucha contra la guerra imperialista y por su transformación en una guerra antiimperialista y de clase. El SSAIC invocó los lemas de hermandad de los trabajadores bolivianos y paraguayos, de la lucha por instalar un gobierno de trabajadores y campesinos y de la Federación de Repúblicas Obreras y Campesinas de América Latina. ${ }^{37}$ El PCP pareció entrar en un círculo vicioso. La aceptación de tal estrategia en las condiciones dadas significaría que los comunistas paraguayos se convirtieran en parias en una sociedad poseída por un delirio patriótico. Mientras, las intenciones de Ibarrola de adaptarse a la situación e interpretar la lucha contra Bolivia como un movimiento antiestadounidense, inevitablemente conduciría a una ruptura con la línea general trazada por la Comintern. La situación del PCP se complicó aún más por factores subjetivos, ya que el jefe del Secretariado Sudamericano hizo todo lo posible para expulsar a Ibarrola de la dirección del PCP.

Una avalancha de etiquetas negativas fue lanzada por Codovilla contra Ibarrola, quien fue tildado como un intelectual pequeño-burgués, incapaz de conducir algún trabajo serio, otro caudillo individualista que no tenía nada que ver con el comunismo. Según el organismo regional, el PCP era más "un grupo escaso de camaradas que un partido auténtico en el sentido orgánico de esta palabra”, y el único responsable de la situación era Ibarrola. De hecho, todas las fallas del PCP enumeradas por Codovilla, fueron sacadas del análisis de las condiciones de organización del PC de Paraguay enviado por Ibarrola a la Comintern. Sin embargo, esta vez la responsabilidad fue personificada en el mismo dirigente del PCP. ${ }^{38}$

Codovilla prefería dirigirse directamente a los miembros del CC del PCP ignorando al secretario general del partido. En efecto, la actividad del SSAIC fue una abierta violación de los principios básicos de disciplina dentro de la Comintern y destruyó la disciplina interna del PCP. La respuesta del Secretario General fue rápida: expresó su renuencia a leer los comentarios críticos del Secretariado Sudamericano a los conceptos que había presentado en el artículo "Mi viaje a Rusia", ya que estos comentarios no se enviaron a la Secretaría del PCP ni a él personalmente. Ibarrola también ofendió a Codovilla en público llamándolo "un viejo estafador italiano". Tal comportamiento fue aprovechado por Codovilla, ya que le dio un pretexto para plantear otra vez la cuestión del envío de un delegado a Paraguay para liquidar la crisis. Obviamente, en este caso, podía apoyarse en los Estatutos de la Comintern que permitían una injerencia directa de los organismos regionales y superiores en la vida interna de las secciones en caso de desobediencia visible a la 'disciplina internacional'.

\footnotetext{
36 Acta №15 de la sesión del Secretariado Sudamericano de la Comintern. 19 de diciembre de 1928. RGASPI, Moscú. F. 503, inv. 1, exp. 21, fs. 121, 123.

37 Materiales sobre la actividad de los partidos [comunistas] preparados para el próximo pleno (para la comisión que prepara el primer punto de la agenda). El P.C. de Paraguay. RGASPI, Moscú. F. 495, exp. 117, exp. 2, f. 16.

${ }^{38}$ Idem.

39 Acta № 15 de la sesión del Secretariado Sudamericano de la Comintern. Buenos Aires, 19 de diciembre de 1928, f. 120; CC del PCP al Secretariado Latino del CEIC. Asunción, 5 de julio de 1929. RGASPI, Moscú. F. 503, inv. 1, exp. 6, f. 40 .
} 
Para aumentar las tensiones, intentó convencer a los miembros del SSAIC de que Ibarrola "había intimidado a todos los buenos camaradas"; se apoyaba en un grupo de simpatizantes entre los estudiantes, y amenazó con la expulsión a "elementos con buenas actitudes comunistas". "Este es un regalo en un momento de evidente peligro militar", insistió Codovilla y, finalmente, logró su objetivo: el Secretariado Sudamericano aprobó la idea de enviar un delegado a Paraguay. Rodolfo Ghioldi, otro miembro del Secretariado, propuso evitar posibles errores al enviar a alguien "con poder", es decir, al propio Codovilla, quien de inmediato le pidió que le otorgara todos los derechos para "ayudar" a los miembros del PCP en su lucha antibélica. Aunque Ghioldi nunca lo expresara de manera abierta, sus motivos eran visibles: el papel desempeñado por Codovilla en la crisis interna del Partido Comunista de Argentina, fue ambiguo, y Ghioldi ni su grupo podían confiar plenamente en el nuevo Secretario del SSAIC. Sin embargo, fue Codovilla quien viajó a Paraguay. ${ }^{40}$

La obstrucción a los fondos para el PCP, fue otro elemento crucial en el ataque del SSAIC contra Ibarrola. El dinero (mil dólares) para el PCP ya había sido enviado por el CEIC, sin embargo, Codovilla no se lo entregó al partido para, así, levantar una actitud negativa dentro del PCP contra su Secretario General. Quedó claro que no se entregaría el dinero a Asunción hasta que el partido derrocara a Ibarrola del liderazgo. Sin embargo, en la mismísima sesión del CC del PCP que expulsó a Ibarrola, el tesorero del Partido Comunista, Valenzuela, afirmó que "había recibido $\$ 100$ en $\mathrm{m}$ [oneda] arg[entina] (1875 en $\mathrm{m}$ [oneda] n[acional] paraguaya) de c. Codovilla como una ayuda prestada por el Par[tido] Comunista argentino a nuestro partido". ${ }^{41}$ Aún más, el secretario del SSAIC hizo caso omiso a su propia promesa de ayudar a la familia de Ibarrola (su esposa y los seis hijos) durante el largo viaje del dirigente del PCP hacia Moscú. Según Ibarrola, Codovilla no había enviado ni un centavo durante los cinco meses de su ausencia de Asunción y que esto había hecho a su familia literalmente "morir de hambre". ${ }^{2}$

Este último (Ibarrola) consideró la cuestión financiera como la razón principal del conflicto con el Secretariado. ${ }^{43}$ Finalmente, Codovilla llegó a Asunción sin contactar previamente a Ibarrola. Inmediatamente estableció contactos con los opositores al Secretario General. En la reunión del Comité Central del PCP el 28 de diciembre de 1928 (organizada sin el permiso de Ibarrola), Codovilla esbozó una plataforma política para ser utilizada por el Partido Comunista de Paraguay "de acuerdo con la disciplina internacional". Tras estas declaraciones, los participantes de la reunión reconocieron sus "errores" y afirmaron estar dispuestos a "trabajar colectivamente por el engrandecimiento de nuestro Partido bajo el control del Sec[retariado] S[udamericano] de la I.C." ${ }^{44}$ La reorganización del partido implicó el ascenso de Martín Báez al cargo de Secretario General (más tarde, su hijo sería el único militante paraguayo aceptado en la famosa escuela de cuadros de la Comintern, la Escuela Leninista Internacional), mientras que Ibarrola se convirtió en editor en jefe del diario "Los Comuneros". ${ }^{45}$ Sin embargo, estos

\footnotetext{
40 Acta № 15 de la sesión del Secretariado Sudamericano de la Comintern, 122.

${ }^{41}$ Acta №2 de la sesión del CC del PCP. Asunción, 6 de enero de 1929. RGASPI, Moscú. F.495, inv.117, exp.6, f.17.

${ }^{42}$ L. Ibarrola a la Internacional Comunista. 30 de enero de 1929. RGASPI, Moscú. F.495, inv.117, exp.6, f.28.

43 L. Ibarrola al Secretariado de la Internacional Comunista. Enero de 1929. RGASPI, Moscú. F.495, inv.117, exp.6, f.25.

44 Acta №1 de la sesión del CC del PCP. RGASPI, Moscú. F. 495, inv.117, exp.6, f.14.

45 Ibid., 15.
} 
cambios no fueron más que una hábil maniobra táctica. Codovilla tomó en cuenta la considerable influencia del ex líder entre los comunistas paraguayos, sabía que éste no aceptaría los cambios y prefirió esperar los futuros errores de Ibarrola. No tuvo que esperar mucho.

El 6 de enero de 1929, Ibarrola expulsó del partido a los simpatizantes de la línea del SSAIC (Martín Báez, Moisés Drelijman y Víctor Valenzuela) y los acusó de dividir al PCP en el momento crucial de la inevitable guerra entre Bolivia y Paraguay. Según su afirmación, el Secretariado Sudamericano estaba apoyando un motín de personas que no tenían "prestigio porque eran unos ignorantes, incapaces de llevar adelante un Partido político". ${ }^{6}$ Ibarrola estaba convencido (iy con plena razón!) de que el principal motivo de tal actitud del Secretariado eran los sentimientos personales de Codovilla, que no podía olvidar las acusaciones del líder comunista paraguayo sobre cuestiones financieras y las declaraciones de que "los comunistas como hermanos debemos desterrar la mentira"."

El derrocado Secretario General del PCP apeló a la Comintern y acusó a Codovilla de causar divisiones; exigió poner fin a la "intervención indebida en las cuestiones internas del Partido". Ibarrola señaló que no ponía en duda el derecho del SSAIC de participar en la elaboración de la "línea política", Comintern habían excedido sus competencias y asumido la autoridad de los cuerpos supremos de la III Internacional al intervenir en las cuestiones internas del Partido y actuar contra el Secretario del PCP reconocido como tal por el Congreso de la IC. "El "El Partido sabe cómo debe obrar, expulsar a los Judas y no premiarlos, como él [Codovilla] pretendió hacerlo", 50 fueron las palabras de Ibarrola enviadas a Moscú. El comunista paraguayo expresó su disposición a obedecer a "la Internacional de Moscú", pero negó la sumisión a los dictados de "la Internacional de Buenos Aires". ${ }^{1}$

Mientras tanto, los adversarios de Ibarrola declararon que el líder había decidido renunciar el 2 de enero y formar otro Partido Comunista, no adherido a la Comintern y editar otra vez el periódico Los Comuneros como el órgano del PC de la República Paraguaya. ${ }^{52}$ Afirmaron que Ibarrola deseaba mantener estos planes en secreto hasta que la Comintern hubiera tomado una decisión final.

Después de la expulsión de Ibarrola del PCP, sus perseguidores se dirigieron al Secretariado Sudamericano solicitando una confirmación de que su partido era la única sección oficialmente reconocida por el CEIC. Los motivos para expulsar al "traidor" y "usurpador" Ibarrola fueron enumerados en la resolución, entre ellos figuraban "la ausencia absoluta de disciplina comunista; transformación del órgano partidario en un órgano personal y su usurpación;

\footnotetext{
${ }^{46}$ L. Ibarrola a la Internacional Comunista, 28.

47 Idem.

${ }^{48}$ L. Ibarrola al Secretariado de la Internacional Comunista, 27; L. Ibarrola a la Internacional Comunista, 29.

${ }^{49}$ CC del PCP al Secretariado Latino del CEIC. Asunción, 5 de julio de 1929, 40.

${ }^{50}$ L. Ibarrola al Secretariado de la Internacional Comunista, 27.

51 Estenograma del informe de Humbert-Droz al Secretariado Sudamericano sobre resultados de la Conferencia Sindical en Montevideo y sobre la Primera Conferencia Comunista Latinoamericana, 12 de julio de 1929. RGASPI, 495/79/53. Citado en: Nikolai P. Kalmykov et al (eds.), Komintern i Latinskaia Amerika, Moscú, Nauka, 1997, 119.

52 Acta № 2 de la sesión del CC del PCP. Asunción, 6 de enero de 1929. RGASPI, Moscú. F. 495, inv.117, exp.6, f.15.
} 
violación de las decisiones tomadas por el CC; una lucha en contra del CC y en contra del Partido". 53

El Secretariado Sudamericano dio su aprobación inmediata a la expulsión de Ibarrola y la hizo pública a través de la revista del Secretariado. ${ }^{54}$ Además, los miembros del SSAIC decidieron fortalecer sus argumentos publicando los materiales del "caso Ibarrola" en tres números de "La Correspondencia Sudamericana" precedidos por el informe de Codovilla sobre la situación política y económica en Paraguay. ${ }^{55}$ El derrocado Secretario General calculó que iba a recibir el apoyo del CEIC y se negó categóricamente a entregar los sellos y el archivo del PCP a los nuevos líderes. ${ }^{56}$

Sin embargo, el Lender-Secretariado Latinoamericano de la Comintern no tenía la intención de escuchar los argumentos de Ibarrola, suponiendo que el SSAIC en Buenos Aires "estaba siguiendo la situación". "La reacción de los tutores moscovitas del comunismo sudamericano fue natural: no podían desacralizar a los líderes de sus propias estructuras regionales quienes, a su vez, habían sido asignados recientemente a sus cargos. De lo contrario, habría significado la continuación de la crisis aguda en el PCA y en el SSAIC. Humbert-Droz explicó que ni el Secretariado Sudamericano ni el CEIC tenían intenciones de luchar contra el CC del PCP si "siguiera el camino comunista y cumpliera su misión como jefe de una sección de la Internacional Comunista", además, el comunista suizo prometió ayuda y consejos al PCP para "tener una mejor orientación en los complicados problemas [...] de la lucha revolucionaria y el desarrollo del Partido Comunista en un auténtico partido proletario". Ibarrola fue declarado un "renegado fuera de las filas de la Internacional Comunista y no tener nada en común con él". Humbert-Droz incluso encontró una explicación cómoda para los contactos establecidos por Codovilla con los oponentes de Ibarrola: el Secretario del SSAIC tenía que ser muy prudente en las condiciones de los preparativos de la guerra y la vigilancia policial sobre los líderes de las organizaciones revolucionarias; según Moscú, fueron "medidas de seguridad elementales". ${ }^{8}$

Con la intención de fortalecer el prestigio del Secretariado Sudamericano y mostrar la responsabilidad de las secciones nacionales en obedecer la decisión tomada en Buenos Aires, el Secretariado del CEIC acusó al ex Secretario General del PCP de negarse a seguir las resoluciones aprobadas por el SSAIC, y subrayó la imposibilidad de utilizar al Ejecutivo de la Internacional Comunista contra sus estructuras regionales. "Moscú también se refirió a todos los "trabajadores revolucionarios" contra una actividad "dentro de las fuerzas comunistas dirigidas por Ibarrola”, expresando que cualquier mención del nombre de la III Internacional y de su autoridad por parte de Ibarrola significaría "una usurpación y una mentira". Mientras el

53 "La expulsión de Ibarrola", La Correspondencia Sudamericana, 9, Buenos Aires, 1929, 21.

54 CC del PCP al Secretariado Sudamericano de la Comintern. Asunción, 16 de Febrero de 1929. RGASPI, Moscú. F.495, inv.117, exp.6, f. 32.

${ }^{55}$ La Correspondencia Sudamericana, 7-11, Buenos Aires, 1929.

56 Acta № 2 de la sesión del CC del PCP, 15; Acta № 3 de la sesión del CC del PCP. Asunción, 27 de enero de 1929. RGASPI, Moscú. F.495, inv.117, exp.6, fs. 17-18.

57 Secretario del Secretariado Latinoamericano del CEIC al Bureau Sudamericano. Moscú, 11 de marzo de 1929. Borrador de la resolución sobre el caso de Ibarrola propuesto por el Secretariado Latinoamericano. RGASPI, Moscú. F.495, inv. 117, exp. 1, fs. 6, 8.

${ }^{58}$ Secretario del Secretariado Latinoamericano del CEIC al Secretariado del PCP. Moscú, 18 de Febrero de 1929. RGASPI, Moscú. F.495, inv. 117, exp. 1, f. 6.

${ }^{59}$ Secretariado de la IC, resolución sobre el caso Ibarrola. RGASPI, Moscú. F.495, inv, 117, exp.1, f. 13. 
“caso Penelón” aún estaba en discusión, el CEIC estaba convencido de que era necesario mantener la unidad del PCA como base para el comunismo sudamericano en su conjunto. También quedaba bastante claro que Victorio Codovilla era una persona clave no sólo a escala continental, sino también en el movimiento comunista mundial.

Sin embargo, ni Ibarrola podría jugar en Paraguay el mismo papel que Penelón en Argentina, ni su Partido era lo suficientemente significativo. La situación cambió drásticamente después del VI Congreso Mundial y el inicio de la estalinización de la Comintern y, desde ese momento en adelante, Moscú consideró de suma importancia demostrar que el comportamiento disidente dentro del comunismo internacional sería derrotado por todos los medios.

Además, Ibarrola cometió un grave error táctico al no saber casi nada sobre la situación interna dentro de la Comintern. El líder derrocado del PCP se presentó como un confidente de la III Internacional que había recibido la confirmación de plena confianza personal a su regreso de Moscú y alegó que fue recibido por el "Comisario de Asuntos Exteriores Humbert-Droz" (i!). ${ }^{60}$ El llamado de ayuda de Ibarrola al comunista suizo no pudo darle ninguna posibilidad de triunfo en su conflicto con Codovilla, ya que el mismo Humbert-Droz era en ese momento víctima de los ataques de Stalin como uno de los líderes "derechistas" y "vacillantes" dentro de la Comintern. En otras circunstancias, Humbert-Droz podría haber analizado objetivamente la situación, pero ahora se enfrentaba a la necesidad de salvarse a sí mismo; la eventual defensa del "chauvinista" paraguayo sólo habría deteriorado su propia situación en la Comintern.

Codovilla, a su vez, aprovechó la oportunidad para demostrar que Ibarrola no vio ninguna diferencia entre la URSS y la Internacional Comunista, refiriéndose a la mención de HumbertDroz como "Comisario de Asuntos Exteriores" hecha varias veces por Ibarrola. Se suponía que esto serviría como otra prueba de las "capacidades limitadas" de Ibarrola y "la falta de serenidad política". El triunfo personal de Codovilla, la destitución de Ibarrola y su expulsión del Partido Comunista, fueron presentados por el SSAIC como un acto fundamental para la formación de una nueva cúpula proletaria del CC del PCP. ${ }^{61}$ Por lo tanto, el trabajo antes realizado por Pedro Romo fue negado, y todos los logros de los comunistas paraguayos en la década de 1920 fueron tachados.

\section{La transformación del PCP y sus posteriores relaciones con la Comintern}

A partir de ese momento, la historia del PCP se volvió a escribir como tabla rasa. El jefe del Secretariado Sudamericano, Codovilla, el indiscutible 'hombre de Moscú' en el comunismo latinoamericano desde finales de los 1920s, se convirtió en el "padre-fundador" que sostuvo con una especie de "modestia": "Hemos echado las bases para el desarrollo del futuro movimiento comunista". ${ }^{62}$ Por segunda vez en tan sólo un año, el comunista argentino logró cambiar el curso de los acontecimientos para su propio beneficio y el cumplimiento de su propio cargo. La primera vez fue durante la crisis interna en su propio partido, el PCA, y las discusiones sobre el tema emprendidas dentro del CEIC. Codovilla había apoyado con fervor a

${ }^{60}$ Informe de V. Codovilla sobre el PCP. 18 de enero de 1929. RGASPI, Moscú. F. 495, inv.117, exp.3, f. 7.

${ }^{61}$ Materiales sobre la actividad de los partidos [comunistas] preparados para el próximo pleno (para la comisión que prepara el primer punto de la agenda). El P.C. de Paraguay. RGASPI, Moscú. F.495, inv.117, exp. 2, f.16.

${ }^{62}$ Informe de V. Codovilla sobre el PCP, 10. 
Penelón. Sin embargo, al observar las perspectivas de una derrota inevitable de su antiguo compañero, el representante del PCA en Moscú cambió drásticamente su actitud e, incluso, logró aparecer ante los ojos de la Comintern y de los PP.CC de Sudamérica como un campeón en la lucha contra la "desviación penelonista" y el defensor de los principios bolcheviques en el PCA.

En el caso paraguayo, también demostró ser capaz de crear una imagen como líder y teórico del movimiento comunista de América del Sur, en plena conformidad con el desarrollo de la III Internacional y el ascenso de Iosif Stalin, cuando Moscú necesitaba más de estos líderes continentales. Sin embargo, el triunfo logrado por Codovilla fue una victoria pírrica. Desde la perspectiva del desarrollo del comunismo sudamericano, Codovilla estuvo lejos de fortalecer secciones nacionales influyentes y capaces, con un alto nivel de autoridad en los respectivos países, exentas de afectaciones aventureras. Esto tuvo que ver directamente con el análisis del conflicto entre Bolivia y Paraguay realizado por el secretario del SSAIC y la conclusión de este de que el PCP que (a pesar de su pequeño número de militantes) tenía una oportunidad real de convertirse en "el único líder de la próxima lucha" y transformar los movimientos de masas "en la lucha por la revolución democrática popular", presentando "consignas adecuadas" en circunstancias de conflictos armados provocados por las contradicciones inter-imperialistas sobre la dominación en América Latina. ${ }^{63}$

Durante la Primera Conferencia Comunista Latinoamericana en Buenos Aires (en 1929) el líder comunista argentino acusó a los comunistas bolivianos y paraguayos de "provincialismo" y subestimación de los problemas internacionales, especialmente de la cuestión de la guerra. Según Codovilla, este fue el principal obstáculo para la agitación comunista entre las masas trabajadoras sobre la esencia imperialista de la guerra y sobre las posibilidades de prevenirla. El jefe del SSAIC acusó a los comunistas bolivianos y paraguayos de haber sido incapaces de cumplir con sus obligaciones revolucionarias, a pesar de que las "condiciones objetivas" para tal trabajo estaban presentes. Codovilla afirmó que las razones principales era la falta de experiencia política del PCP y del Partido Comunista de Bolivia, y la confusión de sus postulados ideológicos. ${ }^{64}$ Declaró que la tarea global de los dos partidos era mostrar su disposición a "luchar contra el imperialismo y sus agentes representados por los gobiernos nacionales".

Paulino González Alberdi, otro miembro argentino del SSAIC, señaló que el comportamiento del PCP y del PCB no era el de los comunistas consecuentes: "Los comunistas tenían miedo a las represiones y no comenzaron a trabajar activamente entre las masas y el ejército". ${ }^{65}$ Estas acusaciones de cobardía causaron conmoción entre los nuevos líderes del PCP, lo que provocó que se esforzaran por la rehabilitación de parte del SSAIC. Como consecuencia, los líderes del PCP perdieron toda comprensión de la realidad, deseando ansiosamente ser declarados auténticos comunistas, sin ser conscientes de cómo cayeron en una euforia a la luz de las futuras victorias. Sin embargo, este tipo de aprensión llevó al partido a una catástrofe. En efecto, los comunistas no tenían medios financieros ni fuerzas para llevar a cabo tales tareas. Las exigencias del SSAIC eran absurdas e inevitablemente llevaban a ambos partidos a nuevos fracasos.

63 Ibid., 11.

${ }^{64}$ Victorio Codovilla, Izbrannye stat’i i rechi, Moscú, Izdatel'stvo politicheskoi literatury, 1970, 63-64.

${ }^{65}$ Citado en Jaritonov, op. cit., 156. 
Inspirados por la lucha de los funcionarios de la Comintern en Moscú y Buenos Aires, los líderes del PCP cambiaron por completo sus tácticas, teniendo en cuenta la ampliación del alcance del partido mientras, socialistas y anarquistas, fueron "desacreditados" por varias derrotas en los sindicatos. ${ }^{66}$ Los comunistas paraguayos estaban tan convencidos de su futura victoria que exigieron se les enviara más material de propaganda. Según ellos, "el nivel de desconfianza de los trabajadores hacia el gobierno y los partidos burgueses" era extremadamente alto, y el único obstáculo para la actividad comunista era la insuficiencia de dinero. ${ }^{67}$ El CC del PCP expresó la esperanza de que el Secretariado Latinoamericano y el CEIC reconocieran el trabajo de su pequeño partido y trataran de ayudarlos con todos los medios en vista del papel crucial de Paraguay en la lucha entre los dos imperialismos.

Sin embargo, las circunstancias para las actividades del PCP fueron absolutamente desfavorables. Si bien hay que dar crédito a Codovilla, quien fue bastante preciso en su análisis de las condiciones locales mientras escribía su informe sobre el viaje a Paraguay, de otro lado, mostró ser incapaz de sacar conclusiones correctas, como tampoco lo hizo el Secretariado Sudamericano. El gobierno paraguayo estaba ejerciendo una fuerte influencia en la opinión pública con el lema de "guerra defensiva", y muchos paraguayos percibieron las actividades de los militares como una "guerra popular".

Según Codovilla, esta situación fue determinada por varios factores. El gobierno fue apoyado por amplias masas que recordaron su larga lucha contra el régimen oligárquico. La campaña contra Bolivia fue percibida como un movimiento contra el imperialismo estadounidense. Los periódicos pro-gubernamentales declararon que Bolivia era una herramienta para los EE.UU., y llamaron a la población a defender al país contra el peligro de la intervención extranjera.

Tratando de poner fin a los sentimientos de oposición, el gobierno otorgó grandes garantías y derechos a sus adversarios políticos que habían sido previamente arrestados por su participación en motines, y realizó una declaración pública que confirmaba la estabilidad de la democracia y las libertades civiles. Una campaña ideológica similar bajo el lema de una "alianza santa para defender la Patria" causó que casi todas las fuerzas políticas y la mayoría de la organización de los trabajadores (por ejemplo, la influyente Liga de los Marineros) apoyaran al gobierno. Incluso aquellos grupos que no tenían actitudes "patrióticas", como los socialistas y los anarquistas, no resistieron los preparativos de guerra, y solo algunos anarquistas desertaron del ejército. ${ }^{6}$ Para organizar la propaganda contra la guerra, los comunistas establecieron contactos con uno de los escasos grupos no conquistados por los sentimientos chauvinistas: el anarquista Consejo de Trabajadores y Estudiantes dentro de la Universidad Nacional, particularmente con los líderes prominentes del Consejo, Obdulio Barthé y Oscar Creydt. El camino hacia la cooperación no fue fácil, ya que era necesario superar la actitud negativa de los miembros del Consejo hacia todos los partidos políticos, incluido el PCP. El Consejo tenía algunas simpatías hacia las ideas comunistas, pero al mismo tiempo sus miembros no querían mantener relaciones ni con el PCP ni con la Comintern.

${ }^{66}$ CC del PCP al Secretariado Latino del CEIC. Asunción, 5 de julio de 1929. RGASPI, Moscú. F.495, inv.117, exp.6, f. 41.

${ }^{67}$ Idem.

${ }^{68}$ Informe de V. Codovilla sobre el PCP, 5-6. 
Las negociaciones entre el PCP y el Consejo de Trabajadores y Estudiantes culminaron en la fundación de un comité conjunto que organizó una campaña de propaganda contra la guerra, sobre la base de los lemas enviados desde Buenos Aires, añadiendo algunas demandas locales. $^{69}$ Antes de este nuevo período de actuación del PCP, desencadenado por la intervención del Secretariado Sudamericano, el gobierno paraguayo le prestó poca atención al PCP, como informó Codovilla a Moscú ${ }^{70}$. Poco después, sin embargo, las autoridades intentaron deshacer este "error", arrestando a algunos militantes del PC. ${ }^{71}$ Más tarde, después de la derrota de la rebelión de 1931, encabezada por los nuevos aliados de los comunistas, el gobierno desencadenó fuertes represiones contra la oposición y casi extinguió al Partido Comunista.

La guerra de Chaco (1932-1935), el conflicto bélico más sangriento en el continente latinoamericano durante todo el siglo XX, resultó ser otro reto para el PCP. El Partido Comunista tenía formulada su actitud frente a ella. Fue expuesta en el Congreso Sindical en Montevideo, en 1929, tres años antes de su inicio. El Congreso había declarado que todo el proletariado de América Latina debía consolidarse "en contra de la amenaza de una guerra que estaba aproximándose para no caer víctima de las ambiciones imperialistas". ${ }^{72}$ Sin embargo, tal actitud estaba destinada al fracaso: dada la escala del conflicto entre Paraguay y Bolivia, ninguna conciliación entre los grupos proletarios era imposible en aquel momento. Peor aún, los comunistas fueron considerados una fuerza antipatriótica y casi traicionera, lo que obstaculizaba aún más las posibilidades de acercarse a la población paraguaya.

El PCP renació como resultado de una Conferencia Nacional celebrada en Lobos (Argentina) en 1934, y los ex anarquistas Aurelio Alcaraz, Obdulio Barthé y Oscar Creydt, se convirtieron en los nuevos líderes del Partido. Es por eso que más tarde insistieron en que el Partido Comunista se había fundado en $1934^{73}$. En este momento el PCP contaba con cerca de 600 militantes. $^{74}$

En tales condiciones, los comunistas paraguayos llegaron a la hora de un nuevo cambio en la política implementada por la Comintern. La inminente aproximación de una guerra mundial, el serio debilitamiento de la clase obrera debido a las persecuciones gubernamentales y divisiones internas, la incapacidad de los Partidos Comunistas para establecer el Poder Soviético durante el llamado 'Tercer período', eran las circunstancias que obligaban a Moscú a abogar por el Frente Popular. En 1934, durante su intervención en el XVII Congreso del Partido Comunista soviético, Stalin admitió que, aunque la tarea estratégica de los comunistas seguía siendo la misma (llegar al poder), debía ser preparada minuciosamente durante meses y años. Sus tesis fueron replanteadas por Georgui Dimitrov en el VII Congreso Mundial de la Comintern; el dirigente del PC mundial propuso diferenciar claramente entre fascismo y democracia burguesa. Los comunistas consideraban a esta última como una sociedad

\footnotetext{
${ }^{69}$ Acta de la sesión del CC del PCP. Asunción, 5 de julio de 1929. RGASPI, Moscú. F.495, inv.117, exp.6, fs. 4344.

${ }^{70}$ Informe de V. Codovilla sobre el PCP, 7.

${ }^{71}$ CC del PCP al Secretariado Latino del CEIC. Asunción, 5 de julio de 1929, 40-41.

72 Rosales, op. cit., 20.

73 Kommunisticheskii Internatsional pered VII V semirnym kongressom (Materialy), Moscú, Partizdat TsK VKP /b/, 1935, p. 407; Campos, op. cit., 207.

74 Jaritonov, op. cit., 153.
} 
imperfecta, sin embargo Moscú les instruía a defenderla de la amenaza fascista y, con este objeto, toleraba una alianza con socialistas, social-demócratas y varios partidos burgueses de carácter antifascista. ${ }^{75} \mathrm{Al}$ mismo tiempo, el frente único obrero debería convertirse en la base para este amplio movimiento democrático y antifascista. La resolución del congreso sobre el trabajo del CEIC declaraba claramente: "El Congreso obliga a todas las secciones de la Internacional Comunista a acabar lo más pronto posible los prejuicios de las tradiciones sectarias que entorpecían encontrar el acceso a los obreros social-demócratas, cambiar los métodos de agitación y propaganda que habían sido abstractos y no habían atraído a las masas, enlazarlos con las reivindicaciones inmediatas y los intereses cotidianos de las masas". ${ }^{76}$ Según el dirigente del Secretariado de América del Sur y del Centro, Van Min, la Comintern entendía perfectamente la diferencia entre los países, sin embargo, la línea general trazada no podía ser reconsiderada. ${ }^{77}$. Esta nueva línea fue cuestionada por varios partidos importantes, entre otros, por el PC de Argentina. Esto fue muy significativo, empero, Moscú logró imponer su línea, por lo menos formalmente.

La realización práctica del Frente Popular resultó ser más difícil, y Paraguay fue una muestra de eso. En 1936, tras la llamada 'Revolución de Febrero', durante el gobierno de coronel Rafael Franco, el PCP logró varios avances aprovechando sus buenas relaciones con las autoridades 'febreristas'. ${ }^{78}$ Fue aprobada la ley sobre la jornada laboral de ocho horas, los trabajadores gozaron las nuevas normas sobre sueldo mínimo, asistencia médica gratuita, así como la reforma agraria. La Comintern tardó mucho en cómo estimar al gobierno de R. Franco, de quien sospechaba mantener simpatías hacia los fascistas italianos y los nazis alemanes. Moscú regañó fuertemente al PCP por sus buenas relaciones con Franco y un tipo de alianza que, al parecer, cuadraba muy bien con la política del Frente Popular proclamada por la Comintern en 1935. De hecho, la alianza del PCP con Franco fue considerada por la Internacional Comunista como un simple intento por recibir patronato gubernamental y no como una expresión del Frente Popular adaptado a las realidades del país sudamericano.

En esas condiciones, los comunistas paraguayos tuvieron que criticar al gobierno franquista pero sin irse al campo de sus adversarios para no perder de nuevo la legalidad. ${ }^{79}$ Sin embargo, muy pronto el PCP se quedó de nuevo sin nada y fue proscrito por la Ley 152, al ser derrocado el gobierno febrerista. ${ }^{80}$

Tras el "caso Ibarrola", el PCP no volvió a estar en la agenda central de la Comintern, y los asuntos paraguayos no fueron discutidos en ninguna de las conferencias comunistas latinoamericanas, aunque los delegados del PCP estaban presentes en varios de estos eventos. Apenas algunas referencias fueron hechas a las condiciones paraguayas en el contexto de la complicada situación del movimiento comunista latinoamericano. ${ }^{81}$

Moscú, sin embargo, no descansaba en juntar más datos sobre las actividades del PCP. Los

${ }^{75}$ Mackenzie, K., Komintern i mirovaia revolutsiia. 1918-1948 gg., Moscú, Tsentrpoligraf, 2008, P. 186.

${ }^{76}$ VII congress Kommunisticheskogo Internatsionala i borba protiv fashizma i voiny, Moscú, Politizdat, 1975, PP.. $360-361$.

77 Komintern i ideia mirovoi revolutsii. Dokumenty. Moscú, Nauka, 2001, P. 897.

${ }^{78}$ Sergei Brilev, "Malen’kaya mirovaia voina v Yuzhnoi Amerike”, Mę̧bdunarodnaya zhizn’, 2, Moscú, 2013, 155185.

${ }^{79}$ Ibid., 170.

${ }^{80}$ Rosales, op. cit., 23.

81 Igor Yanchuk, "Na puti k narodnomu frontu: 3ya konferentsia latinoamerikanskij kommunistov 1934 g.", Latinoamerikanskii istoricheskii almanakh, 3, Moscú, 2002, 151-180. 
documentos del Departamento de Personal de la Comintern contienen muchos datos sobre detenciones y expulsiones de comunistas paraguayos a la Argentina, así como sus biografías. La Comintern, en la década de 1930, no dejó al PCP fuera de su atención, enviando a varios instructores (sobre todo argentinos) al país, aunque la mayoría de ellos no aguantaban las difíciles condiciones del trabajo y regresaba a su patria. No fue así el caso del argentino Humberto Solaro, miembro del PCA y egresado de la Universidad Comunista de Trabajadores del Oriente en Moscú, quien viajó a Paraguay para contribuir a los trabajos del PCP y de su sección juvenil. Se empeñó plenamente en su labor, pero fue detenido y asesinado por la policía. ${ }^{82}$ Otro militante de la Juventud Comunista argentina y chilena, José Eidelstein ("Petizo") fue a Paraguay con el objeto de ayudar a organizar organizaciones juveniles comunistas, pero se sabe muy poco sobre los pormenores de su viaje.

Otro de los emisarios enviados por la Comintern, el argentino Caetano Córdova Iturburo (“Gastón”), logró establecer contactos con el ministro de educación y justicia de Paraguay, Anselmo Peralta, cercano a los grupos de izquierda. Durante las pláticas sostenidas entre Gastón y Peralta, ambos llegaron a la conclusión de que el PCP seguía siendo una fuerza más bien sectaria sin muchas raíces en la sociedad y, además, que los comunistas sobreestimaban sus propias posibilidades. El emisario, obviamente, hizo caso omiso de la culpa de la Comintern en los fracasos de su sección paraguaya. De hecho, lo que el ministro quería era que el PCP, al igual, que los grupos socialistas, se adhieran al partido gubernamental, perdiendo su autonomía política, una cosa imposible de realizar dentro de la táctica cominternista, por lo menos, en el caso paraguayo. Como lo era habitual, Moscú prefirió decir que toda la culpa era del PCP que había "sobreestimado sus fuerzas y subestimado las fuerzas del gobierno". La misma sentencia fue dada en la reunión del Secretariado de Van Min sobre el asunto paraguayo, en febrero de 1936. Además, los miembros del Secretariado, al analizar la historia del PCP, ni siquiera hicieron caso a los años 1924-1932, al afirmar que el partido auténtico apenas apareció en 1932. No solo la actividad de Ibarrola, sino el conflicto entre Ibarrola y Codovilla fueron completamente olvidados. ${ }^{83}$

Los cambios políticos en Paraguay no ayudaron mucho al fortalecimiento del PCP que no lograba convertirse en una fuerza influyente en escala nacional. La aparición de estudiantes dentro de las filas comunistas contribuyó a que el PCP alcanzara 400 militantes, pero esto no podía sustituir ni las células fuera de las zonas urbanas, ni la falta de enlaces fuertes en los gremios, ni la ausencia del dinero para financiar las actividades cotidianas. El PCP estableció algunos contactos con la Confederación de Trabajadores de Paraguay y postuló varios candidatos comunes con la CTP en las elecciones, pero sin lograr muchos éxitos.

\section{Consideraciones finales}

A través de este estudio, hemos analizado las relaciones establecidas entre el movimiento comunista paraguayo con las estructuras regionales de la Comintern en Sudamérica y el estado mayor de la Comintern, la inserción paulatina del PCP en la órbita del comunismo

${ }^{82}$ Lazar Jeifets, Víctor Jeifets, América Latina en la Internacional Comunista, 1919-1943, Santiago de Chile, Ariadna, $2015,585$.

83 “Informe de José Lago Molares sobre la cuestión paraguaya”. Moscú, 28 de febrero de 1936. RGASPI, Moscú. F. 495, inv. 17, exp. 337, fs. 2-4. 
internacional. Este análisis muestra claramente que el tipo de relaciones entre la sección paraguaya de la III Internacional y la Comintern dependió mucho de factores personales, sobre todo, de las contradicciones que habían surgido entre Lucas Ibarrola y Victorio Codovilla, los dirigentes del PCP y el SSAIC, respectivamente. La falta de capacidades políticas demostrada por Ibarrola y su falta de disciplina, al mismo tiempo, entraban en un obvio desacuerdo con las costumbres de la Comintern, sin cuyo patrocinio Ibarrola no tendría ningún futuro político, y la existencia de un Partido Comunista en Paraguay era imposible.

La relación entre el PC paraguayo, el Secretariado Sudamericano de la Comintern y el CEIC fue la clara expresión de una nueva fase de interacción dentro de la III Internacional. La "era romántica" de la Comintern llegó a su fin y fue sustituida por una fase de burocratización profunda, que dependía enormemente de factores subjetivos como la disposición de los líderes y las instrucciones directas. Mientras Stalin era el principal líder del "Partido Comunista Mundial", Victorio Codovilla se convirtió en su pequeña copia en América del Sur durante varios años, y Paraguay fue apenas uno de los primeros escenarios de sus actividades.

Según se desprende del análisis realizado, la Comintern no lograba entender las realidades del lejano y pequeño país sudamericano, y planteaba conceptos casi imposibles para realizar en las circunstancias de Paraguay. No hay que sorprenderse de que el PCP no lograba ganar influencia y aliados fuertes entre sus paisanos, ni de que no se convirtiera en una fuerza que alcanzara, por lo menos, el nivel de prestigio de algunos PP.CC. de América Latina. Moscú logró imponerse dentro del PCP, pero nunca pudo capitalizarlo para hacer del PCP una herramienta útil en el movimiento comunista continental.

\section{Fuentes}

Archivos:

RGASPI Archivo Estatal de Historia Social y Política, Moscú (en ruso: РГАСПИ)

"A compañeros miembros del CEC y a los miembros de todas las Locales del "Partido Revolucionario Venezolano”. Paris, 26 de febrero de 1930. RGASPI, Moscú. F. 495, inv. 107, exp. 16, f. 4.

"Acta de la sesión del CC del PCP". Asunción, 5 de julio de 1929. RGASPI, Moscú. F. 495, inv. 117, exp. 6, fs. 43-44.

"Acta de la sesión del Secretariado Sudamericano de la Internacional Comunista". Buenos Aires, 14 de julio de 1928. RGASPI, Moscú. F. 503, inv. 1, exp. 21, f. 53.

“Acta №1 de la sesión del CC del PCP”. Asunción, s.f. RGASPI, Moscú. F. 495, inv. 117, exp. 6, fs. 14-15.

“Acta №2 de la sesión del CC del PCP”. Asunción, 6 de enero de 1929. RGASPI, Moscú. F. 495, inv. 117, exp. 6, fs.15-17.

“Acta №3 de la sesión del CC del PCP”. Asunción, 27 de enero de 1929. RGASPI, Moscú. F. 495, inv. 117, exp. 6, f.18.

“Acta №4 de la sesión del CC del PCP”. Asunción, 5 de febrero de 1929. RGASPI, Moscú. F. 495, inv. 117, exp.6, f. 20.

“Acta №15 de la sesión del Secretariado Sudamericano de la Comintern”. Buenos Aires, 19 de diciembre de 1928. RGASPI, Moscú. F. 503, inv. 1, exp. 21, fs. 121-123. 
"CC del PCP al Secretariado Latino del CEIC". Asunción, 5 de julio de 1929. RGASPI, Moscú. F. 495, inv. 117, exp. 6, fs.39-41.

"CC del PCP al Secretariado Sudamericano de la Comintern". Asunción, 16 de febrero de 1929. RGASPI, Moscú. F.495, inv. 117, exp. 6, f. 32.

"Declaraciones e informaciones del Camarada Lucas Evangelista Ibarrola de Paraguay". 1928. RGASPI, Moscú. F. 495, inv. 117, exp. 5, fs.1-2;

"Estenograma del informe de Humbert-Droz al Secretariado Sudamericano sobre resultados de la Conferencia Sindical en Montevideo y sobre la Primera Conferencia Comunista Latinoamericana”. 12 de julio de 1929. RGASPI, Moscú. F. 495, inv. 79, exp. 53.

"J. Humbert-Droz al Secretariado Sudamericano de la Comintern". 19 de abril de 1928. RGASPI, Moscú. F. 495, inv. 117, exp. 19, f. 1.

"Informe de P.Romo al CEIC". Buenos Aires, 12 de marzo de 1928. RGASPI, Moscú. F. 495, inv. 117, exp. 6, fs. 2-2ob.

"Informe №4 del Secretariado Sudamericano de la Comintern al Secretariado Latino de la Comintern". Buenos Aires, 5 de julio de 1928. RGASPI, Moscú. F. 503, inv. 1, exp. 19, f. 21.

"Informe de José Lago Molares sobre la cuestión paraguaya". Moscú, 28 de febrero de 1936. RGASPI, Moscú. F. 495, inv. 17, exp. 337, fs. 2-4.

"Informe de V. Codovilla sobre el PCP". 18 de enero de 1929. RGASPI, Moscú. F.495, inv. 117, exp. 3, fs. 5-11.

fs. 3-7.

"L. Ibarrola a J. Humbert-Droz". 5 de junio de 1928. RGASPI, Moscú. F. 495, inv. 117, exp. 6,

“[L. Ibarrola], Memorandum”. 1928. RGASPI, Moscú. F. 495, inv. 117, exp. 5, f. 3.

"L. Ibarrola a la Internacional Comunista". 30 de enero de 1929. RGASPI, Moscú. F.495, inv. 117, exp. 6, fs. 28-29.

"L. Ibarrola al Secretariado de la Internacional Comunista". Enero de 1929. RGASPI, Moscú. F. 495, inv. 117, exp. 6, fs. 25-27.

"Manifesto del Secretariado del CEIC enviado al Comité Ejecutivo del Partido Comunista Paraguayo". Moscú, 19 de abril de 1928. RGASPI, Moscú. F. 495, inv. 117, exp. 1, f. 2.

"Materiales sobre la actividad de los partidos [comunistas] preparados para el próximo pleno (para la comisión que prepara el primer punto de la agenda). El P.C. de Paraguay". RGASPI, Moscú. F. 495, inv. 117, exp. 2, f. 16.

Secretariado de la IC, "Resolución sobre el caso Ibarrola”. Moscú. S.f. RGASPI, Moscú. F.495, inv. 117, exp. 1, f.13.

"Secretario del Secretariado Latinoamericano de la Comintern al Secretariado del Partido Comunista de Paraguay". Moscú, 18 de febrero de 1929. RGASPI, Moscú. F. 495, inv. 117, exp. 1, fs. 5-6.

"Secretario del Secretadiado Latinoamericano del CEIC al Bureau Sudamericano. Borrador de la resolución sobre el caso de Ibarrola propuesto por el Secretariado Latinoamericano". Moscú, 11 de marzo de 1929. RGASPI, Moscú. F. 495, inv. 117, exp. 1, f. 8.

Prensa:

Los Comuneros (Asunción).

La Correspondencia Sudamericana (Buenos Aires).

Bibliografia:

Alexander, Robert J. Alexander R. J. Communism in Latin America. New Brunswick, N. J., Rutgers University Press, 1957. 
Alexander, Robert J. A History of Organized Labor in Uruguay and Paraguay. Greenwood Publishing Group, 2005.

Bonzi, Antonio. Proceso histórico del Partido Comunista Paraguayo (Un itinerario de luces y sombras). Asunción: Arandura Editorial, 2001.

Brilev, Sergei. "Malen'kaya mirovaia voina v Yuzhnoi Amerike”, Mezhdunarodnaya zhizn', N2, 2013, 155-185 (en ruso).

Caballero, Manuel. La Internacional Comunista y la revolución latinoamericana. Caracas: Editorial Nueva Sociedad, 1987.

Campos, Hugo. Panorama del Paraguay. [Asunción]: Editorial Alas, 1970.

Carriere, J., Haworth, N., Roddick, J. The State, Industrial Relations and the Labour Movement in Latin America. Volume 1. Springer, 1989

Codovilla, Victorio. Izbrannye stat’i i rechi. Moscú: Izdatel'stvo politicheskoi literatury, 1970 (en ruso).

Gaona, Francisco. Introducción a la historia gremial y social del Paraguay. Tomo 1. Asunción Buenos Aires: Editorial “Arandu”, 1967; Tomo 2. Asunción: Editora Litocolor, 1987.

Goldenberg, Boris. Kommunismus in Lateinamerika. Stuttgart, Berlin, Köln, Mainz:

Kohlhammer, 1971.

Jaritonov, Vitaly A. Paragvai. Voennopolitseiskaia diktatura i politicheskaia bor'ba. Moscú: Nauka, 1970 (en ruso).

Jeifets, Lazar y Jeifets, Víctor. América Latina en la Internacional Comunista, 1919-1943. Diccionario biográfico. Santiago de Chile: Ariadna, 2015.

Jeifets, Lazar y Jeifets, Víctor. El Partido Comunista de Argentina y la III Internacional. La misión de Williams y los origenes del penelonismo. México, D.F.: Nostromo Ediciones - Universidad Estatal de San Petersburgo, 2013.

Kalmykov, N.P. et al. (ed.). Historia de América Latina, 1918-1945.Moscú: Nauka, 1999 (en ruso). 1998 (en ruso).

Kalmykov, N.P. et al. (ed.). Komintern y América Latina. Sbornik dokumentov. Moscú: Nauka,

Kheifets, Lazar y Kheifets, Victor. "The "International of Moscow" or the "International of Buenos Aires”?", The International Newsletter of Communist Studies. Vol. 18. N.25. 2012. PP. 123-136.

Komintern i ideia mirovoi revolutsii. Dokumenty. Moscú: Nauka, 2001 (en ruso).

Kommunisticheskii Internatsional pered VII Vsemirnym kongressom (Materialy), Moscú: Partizdat TsK VKP /b/, 1935 (en ruso)

Korableva, L.Yu. "Vmeshatel'stvo Ligi Natsii v uregulirovaniie boliviisko-paragvaiskogo konflikta 1928-1938 gg.", Latinoamerikanskii istoricheskii almanakh (2000) (en ruso) (en ruso).

Mackenzie, K. Komintern i mirovaia revolutsiia. 1918-1948 gg. Moscú: Tsentrpoligraf, 2008

Medina, Ricardo. The Left, Peter Lambert\&Andrew Nickson. The Transition to the Democracy in Paraguay. London: Macmillan Press, Ltd., 72-86. (en ruso).

Petrujin, Aleksandr, Churilov, Evgenii M. Kebracho - znachit stoikii. Moscú: Politizdat, 1981

Piemonte, Víctor Augusto. "La Internacional Comunista y los comienzos del Secretariado Sudamericano a través de la sistematización regional del proceso de bolchevización”. Historia Crítica. N.64. Bogotá. 2017. PP. 101-118

Relatorio sobre la actividad enemiga de Oscar Creydt. S.l., abril 1967.

Rosales, Humberto. Historia del Partido Comunista Paraguayo, 1928-1990. Asunción: PCP Editor, 1991. 
VII kongress Kommunisticheskogo Internatsionala i borba protiv fashizma i voiny. Moscú: Politizdat, 1975 (en ruso).

VI kongress Kominterna. Stenograficheskii otchet. Tezisy, resoliutsii, postanovleniia, vozzvaniia. Moscú-Leningrado: Gosizdat, 1929 (en ruso).

Yanchuk, Igor. "Na puti k narodnomu frontu: 3ya konferentsia latinoamerikanskij

kommunistov 1934 g.", Latinoamerikanskii istoricheskii almanakh. № 3. 2002. 151-180 (en ruso)

Zarodov, K.I. (ed.). Kommunisty mira - o svoikh partiiakh. Praga: Mir i sotsializm, 1976 (en ruso). 